\title{
Post-transplant anemia in pediatric patients and its impact on patient and graft survival: single center experience
}

\author{
Osama Gheith; MD ${ }^{1}$, Ehab Wafa; MD $^{1}$, Ayman Refaie; MD ${ }^{1}$, Nabil Hassan; MD ${ }^{1}$, \\ Amani Mostafa; MD ${ }^{2}$, Hussein Sheashaa; MD $^{1}$, Ahmaed Shokeir; MD $^{3}$, Mohamed Kamal; \\ $\mathrm{MD}^{3}$ and Mohamed A. Ghoneim; M.D., M.D. (Hon.), FACS (Hon.) ${ }^{3}$
}

Departments of Nephrology ${ }^{1}$ Immunology ${ }^{2}$ and Urology ${ }^{3}$, Urology and Nephrology Center, Mansoura University, 35516 , Mansoura, Egypt.

\begin{abstract}
Introduction: Post-transplantation anemia (PTA) occurs frequently, with prevalence rates between 20 and $60 \%$ depending on the criteria used for defining anemia.

Aim of the work: We aimed to assess the prevalence of anemia after 6 months of transplantation in pediatric renal transplant patients under different protocols of immunosuppression, and to determine the impact of anemia upon long-term patient and graft survival.

Patients and methods: Based on the data of 108 renal transplants performed in our center, patients were categorized after 6 months according to their hemoglobin $(\mathrm{Hb})$ levels into two groups. The first group with $\mathrm{Hb}$ more than $11 \mathrm{gm} / \mathrm{dl}$ (group I, 29 cases) and the second group with $\mathrm{Hb}$ less than $11 \mathrm{gm} / \mathrm{dl}$ (group II, 79cases). We compared the two groups regarding post transplant complications (rejection episodes, hypertension, diabetes mellitus, infections, hepatic dysfunction, and patient and graft survival.

Results: we found no significant difference between the two groups regarding rejection episodes. However, the percentage of cases with chronic allograft nephropathy was significantly higher in the

\footnotetext{
Correspondence and offprint requests to: Dr Ayman F. Refaie, M.D, Consultant Nephrologist, Urology and Nephrology Center, Mansoura University, 35516, Mansoura, Egypt.

Tel.: 20-50-2262226 ; Fax: 20-50-2263717

E-mail: ayman_refaie@yahoo.com
}

anemic group. The survivors with functioning grafts were significantly higher in cases with normal $\mathrm{Hb}$. Moreover, living cases with graft failure were significantly higher in anemic group .Graft survival rate was better in the non anemic group. However, no difference in patient survival was detected. Also, we found no difference between the two groups regarding post-transplant complications.

Conclusions: From this study, we can conclude that the prevalence of post-transplant anemia is high pediatric renal transplant patients especially those receiving $\mathrm{CNI}$ and $\mathrm{MMF}$, and it was associated with poorer graft outcome but no effect on patient survival .

Key words: Renal post-transplant anemia, long term outcome

\section{Introduction}

Anemia has been implicated as an important risk factor for cardiovascular mortality in patients with CKD [1]. Post-transplantation anemia (PTA) occurs frequently, with prevalence rates between 20 and $60 \%$ depending on the criteria used for defining anemia [2,3].

PTA has been associated with an increased risk for congestive heart failure and left ventricular hypertrophy in kidney transplant recipients [4,5]. Given the high frequency of PTA and that cardiovascular disease is the leading cause of death 
with a functioning renal allograft, persistent anemia may be an important contributor to mortality in this population [6].

The pathogenesis of posttransplant anemia (PTA) is multifactorial, but declining renal function and failing erythropoietin synthesis are suggested to play an important role [7]. Late post transplantation anemia (PTA) has been attributed to renal dysfunction, immunosuppressive drugs, antiviral agents, infections, blood loss, autoimmune hemolytic anemia, chronic inflammatory state and the use of angiotensin-converting enzyme inhibitors [8-10].

The three recent surveys enrolling the largest number of patients reported a prevalence of 30 $40 \%$. Severe anemia, requiring treatment based on current guidelines, is less frequent with prevalence rate of $10-15 \%$ [11-12].

Conflicting views had been published regarding the association between anemia and outcome in kidneytransplanted patients. No significant association was found between anemia and outcome (mortality or graft failure [13]. However, Heinze et al [14] suggested that anemia may be associated with mortality in the kidney-transplanted patients. The occurrence of PTA at 1 year is harmful to patient survival [15]. Moreover, anemia which is a treatable complication is significantly and independently associated with mortality and graft failure in kidney-transplanted patients [16].

Anemia may also contribute to more rapid loss of renal function in patients with impaired renal function [17]. A recent study suggested that anemia significantly predicted the decline of renal function among CKD patients [18], and also among hearttransplant recipients [19]. Furthermore, Gouva et al [20] have recently shown that treating anemia in CKD patients can slow down the decline of renal function.

\section{Aim of the work}

We aimed to assess the prevalence of anemia after 6 months of transplantation in pediatric patients under different protocols of immunosuppression, and to determine the impact of anemia upon long-term patient and graft survival.

\section{Material and methods}

We included 108 pediatric renal transplant recipients (age $\leq 17$ years) who received live donor kidney transplantation in our center in the period between 1983 and 2005. Most, if not all patients, who have undergone kidney transplantation in our center were anemic and spontaneous correction of anemia was noted and nearly completed within 4-6 months. They were categorized according to their hemoglobin $(\mathrm{Hb})$ levels into two groups. The first group with $\mathrm{Hb}>11 \mathrm{gm} / \mathrm{dl}$ (group I, 29 cases) and the second group with $\mathrm{Hb}<11 \mathrm{gm} / \mathrm{dl}$ (group II, 79 cases). Both groups were matched regarding previous blood transfusion.

Methods: Clinical data were reviewed. Demographic data included recipient age and gender; donor age and gender; causes of end-stage renal disease; and HLA-A, B, \& DR mismatching. All recipients were regularly followed up (with mean follow period $120 \pm 12$ months). The follow up visits were frequent early post-transplantation and then gradually spaced. Each visit, the graft function was assessed by serum creatinine, creatinine clearance and urine analysis; in addition to other laboratory investigations including complete blood picture, immunosuppressive drug levels. All recipients were closely and regularly followed up for evaluation of medical or surgical complications. Abdominal and Doppler ultrasound were also performed.

Immunosuppression: Prednisolone was started on the day (-1) of transplantation at a dose of $8.5 \mathrm{mg} /$ $\mathrm{kg}$ and reduced gradually till the smallest dose of $0.15 \mathrm{mg} / \mathrm{kg} /$ day by the end of the $9^{\text {th }}$ month. Azathioprine (Aza) was given in a dose of 3 $\mathrm{mg} / \mathrm{kg} /$ day for old regimen (steroid and aza) and in a dose of $1.5 \mathrm{mg} / \mathrm{kg} /$ day in group of steroid, Aza, and Cyclosporine (CsA). Only CsA was given 2-3 days pretransplantation. CsA was introduced in a dose of $8.5 \mathrm{mg} / \mathrm{kg}$ and it was adjusted to keep the trough level 200-250 ng/ml in the first month, $150-200 \mathrm{ng} / \mathrm{ml}$ in the second month and 100-150 $\mathrm{ng} / \mathrm{ml}$ thereafter. Antibody induction therapy was given to the majority of cases according to our policy. Antibody induction therapy -using basilixmab $20 \mathrm{mg}$ at days 0 and 4 -was added from the late nineties till now. CsA trough level was measured at first using Radio-immune Assay Kits, (Sandoz, Basel, Switzerland), and then using monoclonal specific antibody, (Abbott laboratories, Abbott Park, IL).

Tacrolimus therapy was given at a dosage of $0.1 \mathrm{mg} / \mathrm{kg} /$ day and the dose was adjusted to achieve target whole-blood trough concentrations of 10 $15 \mathrm{ng} / \mathrm{ml}$ during the first 2 weeks then $5-10 \mathrm{ng} / \mathrm{ml}$ thereafter. Tacrolimus concentrations in whole blood were measured by the IMx analyzer (Abbott laboratories, Abbott Park, IL). Mycophenolate Mofetil (MMF) was administered in a dose of 20$30 \mathrm{mg} / \mathrm{kg}$ twice daily.

Graft biopsy was performed if there was any 
clinical suspicion of rejection (unexplained rise of serum creatinine more than $25 \%$ of the basal level). Before 1994, we were defining acute rejection into 3 grades: mild, moderate and severe according to the degree of cellular infiltration in the graft. After 1994, we followed the Banff classification with its modifications (acute and chronic allograft nephropathy).

All acute rejection episodes were biopsy proven and treated by $10 \mathrm{mg} / \mathrm{kg} /$ day methyl prednisolone for 5 days. Steroid-resistant rejection was treated by antithymocyte globulin. Plasmapheresis was added as an adjuvant therapy in cases of accelerated or vascular rejections.

Statistical analysis: Statistical analysis was carried out using IBM-compatible SPSS for windows version 11.5 (SPSS Inc., Chicago, IL). For comparison of continuous data, the T-test was utilized. Chi-square test was employed for comparison of simple proportions. Patient and graft survival were computed using Kaplan-Meier technique. Differences in survival were calculated by the log-rank test. $\mathrm{P}$ value of less than 0.05 was considered statistically significant.

\section{Results}

Table (1) illustrated the donors and recipients characteristics. Majority of recipients were males in their second decade of life while nearly half of the donors were females in their third decade of life. The two groups were homogenous in terms of donor's age, sex; recipient age, prior blood transfusion and pre-transplant hypertension. In addition, no preformed antibodies against donor antigens were detected in the pre-transplant crossmatch of any of the study patients. The techniques employed for re-establishment of urinary continuity were also essentially similar. The two groups were matched regarding the type of primary immunosuppression protocols with the majority being on steroid, CsA and aza.
Rejection episodes: No significant difference was found between the anemic and non-anemic groups regarding either those who experienced single rejection episode $(p=0.079)$; repeated rejections $(\mathrm{p}=0.58)$; cases with acute cellular rejection $(\mathrm{p}=0.95)$, acute vascular rejection $(\mathrm{p}=0.86)$ or chronic rejection $(\mathrm{p}=0.19)$. However, on dealing with anemic patients alone, we observed that the number of cases with chronic allograft rejection was significantly higher among severely anemic patients $(\mathrm{p}=0.025$, table 2$)$.

Outcome: At the last follow up, the survivors with functioning grafts were significantly higher in cases with normal $\mathrm{Hb}(\mathrm{p}=0.013)$. However, living cases with graft failure were significantly higher in anemic group $(p=0.023$, table 3$)$. Graft survival rates were $98.3 \%$ in normal group vs.97.4 \% in anemic group at 1 -year; $98.1 \%$ vs. $96.1 \%$ at 5 -year; and $93.9 \%$ vs. $82.2 \%$ at 10 -year respectively (figure $1, \mathrm{p}<0.001)$. The corresponding patient survival rates were $100 \%$ vs. $98.7 \%$ at 1 -year; $100 \%$ vs. $98.7 \%$ at 5-year; and $100 \%$ vs. $98.7 \%$ at 10 -year respectively (figure $2, \mathrm{p}=0.099$ ).

Graft function: In spite of comparable results of graft function in both groups at one year $(p>0.05)$, the percentage of cases with serum creatinine less than $1.5 \mathrm{mg} / \mathrm{dl}$, was significantly higher in group I ( $p=0.016$ ), while the percentage of cases with serum creatinine more than $3 \mathrm{mg} / \mathrm{dl}$, was significantly higher in group II at the last follow up $(\mathrm{p}=0.01$, table 4). However, both groups were matched regarding cases with normal graft function at the last follow up.

Complications: The two groups were comparable regarding post-transplant complications especially diabetes mellitus; serious bacterial infections, hepatic problems and hypertension $(\mathrm{p}>0.05$, table 5). Two cases (2.6\%) died mostly due to cardiovascular causes in anemic group while no mortality was reported among patients of the other group. Moreover, no single case of malignancy was reported.

Table 1: Characteristics of donors and recipients among patients of the two groups

\begin{tabular}{|c|c|c|c|}
\hline & $\begin{array}{c}\text { Group }(\mathrm{I}) \\
\text { Normal Hb} \\
N=29\end{array}$ & $\begin{array}{c}\text { Group }(I I) \\
\text { Anemic group } \\
N=79\end{array}$ & $p$ value \\
\hline Mean age of donors (years) & $34.1 \pm 9.7$ & $36.5 \pm 10$ & 0.24 \\
\hline Donor sex (male/female) & $10 / 19$ & $34 / 45$ & 0.42 \\
\hline Mean age of recipients (years) & $15.07 \pm 2.4$ & $13.9 \pm 3.3$ & 0.39 \\
\hline Recipient sex (male/female)* & $20 / 9$ & $55 / 24$ & 0.94 \\
\hline \multicolumn{4}{|l|}{ Original kidney disease: } \\
\hline -Immunological causes & 6 & 10 & 0.24 \\
\hline
\end{tabular}


Pretransplant hypertension

Pretransplant blood transfusion

Pretransplant dialysis

HLA type I $\geq 50 \%$ match

type II $50 \%$ match

Type of immunosuppression

-CNI-free

-CsA-based

-Tac-based

12
15
23
26
26

2
25
2

$\begin{array}{cc}1 & 0.35 \\ 69 & 0.87\end{array}$

* Only significant variable with multivariate analysis

Table 2. Rejection episodes in both groups

\begin{tabular}{|c|c|c|c|c|}
\hline & \multicolumn{2}{|c|}{$\begin{array}{c}\text { Group }(I) \\
\text { Normal Hb } \\
N=29\end{array}$} & \multirow{2}{*}{$\begin{array}{c}\text { Group }(\text { II }) \\
\text { Anemic group } \\
N=79 \\
21\end{array}$} & \multirow{2}{*}{$\begin{array}{c}p \text { value } \\
0.79\end{array}$} \\
\hline One rejection & & & & \\
\hline$\geq 2$ rejections & & & 4 & 0.58 \\
\hline $\begin{array}{l}\text { Type of rejections } \\
\text {-Acute vascular } \\
\text {-Acute cellular } \\
\text {-Chronic allograft nephropathy }\end{array}$ & & & $\begin{array}{c}2 \\
24 \\
19\end{array}$ & $\begin{array}{l}0.95 \\
0.86 \\
0.19\end{array}$ \\
\hline \multicolumn{5}{|c|}{ Rejection episodes in anemic patients } \\
\hline & $\begin{array}{l}\text { Mild anemia } \\
\qquad N=25\end{array}$ & $\begin{array}{l}\text { Moderate anemia } \\
\qquad N=21\end{array}$ & $\begin{array}{l}\text { Severe anemia } \\
\quad N=33\end{array}$ & $p$ value \\
\hline One rejection & 8 & 2 & 21 & 0.29 \\
\hline$\geq 2$ rejections & 1 & 2 & 1 & 0.29 \\
\hline $\begin{array}{l}\text { Type of rejections } \\
\text {-Acute vascular } \\
\text {-Acute cellular } \\
\text {-Chronic allograft nephropathy }\end{array}$ & $\begin{array}{l}2 \\
6 \\
3\end{array}$ & $\begin{array}{l}0 \\
5 \\
3\end{array}$ & $\begin{array}{c}0 \\
13 \\
13\end{array}$ & $\begin{array}{c}0.17 \\
0.17 \\
0.025\end{array}$ \\
\hline
\end{tabular}

Table 3. Condition at last follow up of patients who continued primary immunosuppression

\begin{tabular}{|c|c|c|c|}
\hline & $\begin{array}{c}\text { Group }(I) \\
\text { Normal Hb } \\
N=29\end{array}$ & $\begin{array}{c}\text { Group }(I I) \\
\text { Anemic group } \\
N=79\end{array}$ & $p$ value \\
\hline Live + function graft & $28(96.6 \%)$ & $57(72.2 \%)$ & 0.013 \\
\hline live+ dialysis & $1(3.4 \%)$ & $20(25.3 \%)$ & 0.023 \\
\hline Died+ function graft & 0 & $1(1.3 \%)$ & 0.056 \\
\hline Died+ failed graft & 0 & $1(1.3 \%)$ & 0.056 \\
\hline
\end{tabular}


Table 4. Clinical grading of anemic vs. non anemic patients (basal and at the last follows up)

\begin{tabular}{|c|c|c|c|}
\hline & $\begin{array}{c}\text { Group }(\mathrm{I}) \\
\text { Normal Hb} \\
N=29\end{array}$ & $\begin{array}{c}\text { Group }(\text { II }) \\
\text { Anemic group } \\
N=79\end{array}$ & $p$ value \\
\hline \multicolumn{4}{|l|}{ At one year } \\
\hline Grade $1 \mathrm{cr}^{*}<1.5 \mathrm{mg} / \mathrm{dl}$ & $24(82.8 \%)$ & $70(88.6 \%)$ & 0.63 \\
\hline Grade $2 \mathrm{cr} 1.5---3 \mathrm{mg} / \mathrm{dl}$ & $5(17.2 \%)$ & $8(10.1 \%)$ & 0.5 \\
\hline Grade $3 \mathrm{cr}>3 \mathrm{mg} / \mathrm{dl}$ & 0 & $1(1.3 \%)$ & 0.59 \\
\hline \multicolumn{4}{|l|}{ Last follow up } \\
\hline Grade $1 \mathrm{cr}<1.5 \quad \mathrm{mg} / \mathrm{dl}$ & $6(20.75 \%)$ & $19(24.1 \%)$ & 0.71 \\
\hline Grade 2 cr $1.5---3 \mathrm{mg} / \mathrm{dl}$ & $20(69 \%)$ & $32(40.5 \%)$ & 0.016 \\
\hline Grade 3 cr $3-5$ & $3(10.3 \%)$ & $28(35.3 \%)$ & 0.01 \\
\hline
\end{tabular}

*Serum creatinine

Table 5. Types of serious complications encountered among the two groups

\begin{tabular}{|c|c|c|c|}
\hline & $\begin{array}{c}\text { Group }(\mathrm{I}) \\
\text { Normal } \mathrm{Hb} \\
N=29\end{array}$ & $\begin{array}{c}\text { Group }(\text { II }) \\
\text { Anemic group } \\
N=79\end{array}$ & $p$ value \\
\hline Malignancies & 0 & 0 & \\
\hline Hepatic impairment & $2(6.9 \%)$ & $1(1.3 \%)$ & 0.35 \\
\hline Post-transplant Hypertension & $18(62.1 \%)$ & $48(60.8 \%)$ & 0.92 \\
\hline Posttx diabetes mellitus & $1(3.4 \%)$ & $1(1.3 \%)$ & 0.95 \\
\hline Bacterial infections & $1(3.4 \%)$ & $7(8.9 \%)$ & 0.59 \\
\hline
\end{tabular}

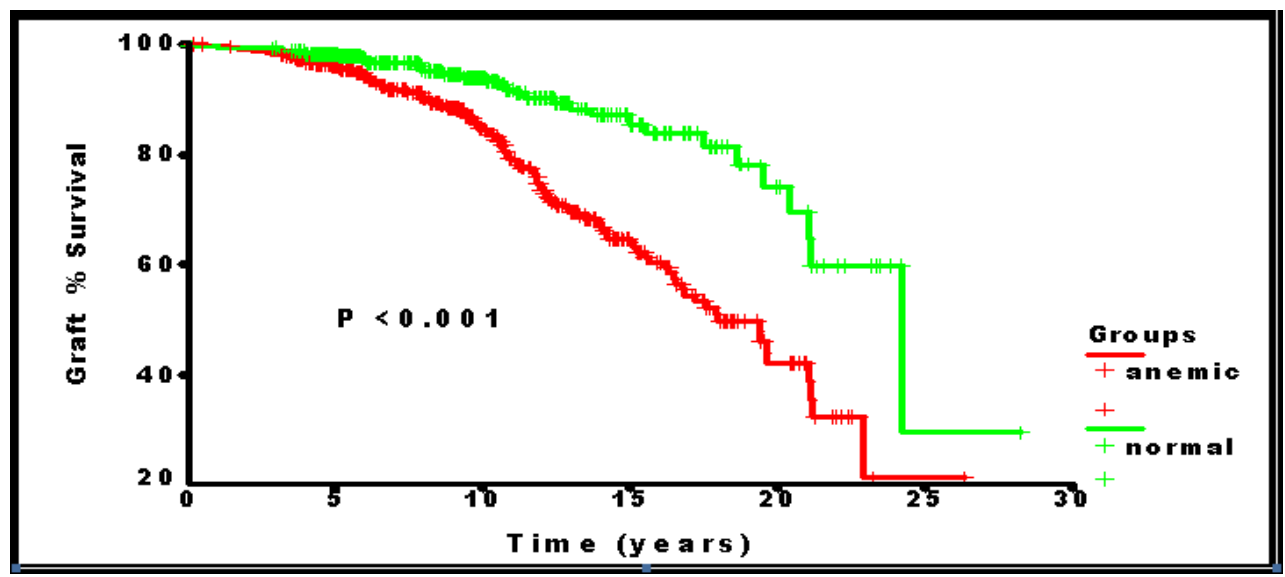

Fig. 1. Graft survival in anemic and cases with normal hemoglobin.

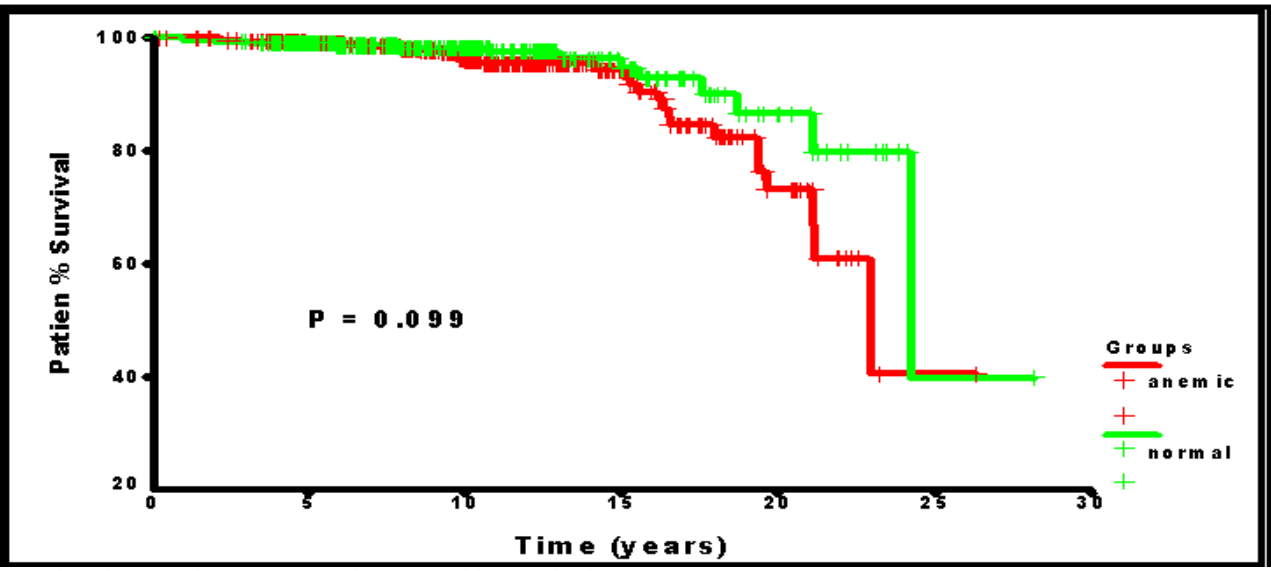

Fig. 2. Patient survival in anemic and cases with normal hemoglobin. 


\section{Discussion}

Anemia in pre-transplant patients usually is a result of erythropoietin (EPO) deficiency, resistance to EPO, iron deficiency (either absolute or functional), and/or blood loss [21-24].

It is reported that anemia is a common problem in kidney transplant recipients and it is an independent risk factor for post transplant left ventricular hypertrophy and cardiovascular diseases [25-27]. The incidence of cardiovascular events (myocardial infarction, cardiovascular death, angina, congestive heart failure) is $35 \%$, less likely in the first six months after transplantation in diabetic transplant recipients with hematocrit $30 \%$ compared to those with lower hematocrit levels [23].

Out of 108 pediatric renal transplant recipients enrolled in this study, we found that anemic patients (according to WHO classification of anemia) represented $53.7 \%$ (31.6\% were mildly anemic, $26.5 \%$ were moderately anemic and $41.7 \%$ were markedly anemic). These results were higher than that reported by large multi-institutional studies which reported lower prevalence of anemia 30-40\% at various times after transplantation [24] and $38.6 \%$ in another European study from 72 European centers of kidney transplant recipients [11]. Moreover, the prevalence of severe anemia was $8.5 \%$ compared to $41.7 \%$ in the present study.

However, shah et al [8] reported that there is a high prevalence of anemia among transplant population, in $45 \%$ of cases. The high prevalence of PTA cannot be attributed to uncorrected pretransplant anemia of CKD [29].

This coincides with our suggestion that although most of our patients were anemic at the time of transplantation, yet this factor alone can not be implicated as a sole factor in genesis of posttransplant anemia. Anemia among our patients might be explained by multiple factors: female gender; calcineurin inhibitors, azathioprine, mycophenolate mofetil, poor graft function, acute rejection episodes, recent infection, and the use of ACE inhibitors and angiotensin II receptor blockers [30]. Patients who were receiving CsA based protocols were associated with lower $\mathrm{Hb}$ levels especially if associated with MMF or azathioprine which could be explained by their negative effect on the bone marrow [31] which was matched with findings of Yorgin et al 2002 Who reported that cyclosporine use was associated with lower $\mathrm{Hb}$ levels, an observation previously described in children [32]. Multivariate analysis of the previous factors showed that only the recipient's sex plays independently among our patients.
In an Egyptian survey [33], they found that $47 \%$ of Egyptian healthy adolescent girls and boys were anemic which decreased to $30 \%$ by the year 2000 . Poor eating habits are the main reason for the high rates of anemia among adolescents in Egypt.

The high prevalence of posttransplant anemia cannot be attributed to uncorrected pretransplant anemia of CKD as the prevalence at five years after kidney transplantation ranges from $30-35 \%$ in recipients with functioning allograft [25].

The antiproliferative agent, azathioprine, is well known to cause bone marrow depression, and despite a different mechanism of action, MMF was observed to cause similar levels of anemia [28]. MMF use had demonstrable association with anemia especially when combined with CsA which was matched with findings of others [29]. Cyclosporine use was associated with lower $\mathrm{Hb}$ levels, an observation previously described in children [30].

At the last follow up, we observed that the survivors with functioning grafts were significantly higher in cases of group I $(\mathrm{p}=0.013)$. However, living cases with graft failure $(25.3 \%)$ were significantly higher in group II $(\mathrm{p}=0.023)$. Along the whole period of follow up, graft survival rates were significantly higher in group I ( $p<0.001)$, however, the corresponding patient survival rates were comparable in both groups $(\mathrm{p}=0.099)$.

Regarding graft survival, our results were matched with that reported by Molnar et al [16] who showed that, in a single center Hungarian study of 938 kidney transplant recipients, the long term effects of anemia on patient and graft survival. During a follow-up of approximately 4 years, 79 patients $(8.4 \%)$ returned to dialysis and 118 patients $(12.6 \%)$ died with $30 \%$ of deaths resulting from infection, $23 \%$ from cardiovascular disease, and $18 \%$ from malignancy. In spite of heterogeneity of immunosuppression, they concluded that anemia predicted graft failure and mortality, independently of estimated glomerular filtration rate, age, gender, time on dialysis, and other co-morbidities. Similarly, Chhabra et al [31] showed that PTA was associated with worse patient and graft survival. Molnar et al [16] demonstrated that the presence of anemia was associated with poor survival and graft failure in kidney transplant recipients with 1.69 times higher chance to die within 4 years; and 2.46 times higher chance to return to dialysis during the same follow-up period than patients without anemia. Regarding patient survival, our results were matched with the results of Winkelmayer et al [32] who did not find significant association between mortality and serum $\mathrm{Hb}$. 
Cases with acute cellular rejection were higher in the anemic group but this did not rank to statistical significance $(p=0.06)$. A finding which was matched with that reported by Chhabra et al [30] who showed that PTA was associated with higher rates of acute rejection when compared with nonanemic recipients.

However, the percentage of cases with chronic allograft nephropathy was significantly higher in the anemic group $(p=0.001)$. The commonest cause of allograft loss is death of patients with functioning allograft (mostly due to cardiovascular events). Moreover, cardiovascular risk factors are also very relevant to the second most common cause of allograft loss (chronic allograft nephropathy) $[33,5]$. Similar to the CKD population, cardiovascular comorbidities are the leading causes of death in kidney transplant patients [34]. Anemia lead to hyperkinetic circulation, thicker left ventricular wall and congestive heart failure in kidney transplant patients. These factors were independent predictors of mortality in transplant population [19].

Our study has demonstrated that cases with graft failure increased significantly with advancement of anemia. This also was matched with that reported by Molnar et al [31] as they showed that each $1 \mathrm{~g} / \mathrm{L}$ decrement in the level of serum hemoglobin increased the odd ratio of graft failure by $1.9 \%$ during the 46 months follow-up period.

In spite of comparable results of graft function in both groups at one year $(p>0.05)$, by time the percentage of cases with normal graft function was significantly higher in the non anemic group $(p=0.001)$, while the percentage of cases with graft dysfunction was significantly higher in the anemic group at the last follow up ( $\mathrm{p}=0.001)$.

Several studies suggested that treating anemia can slow down the decline of renal function in patients with chronic kidney failure [35]. It was also notable that chronic hypoxia and oxidative stress are profibrogenic stimuli for tubular cells and interstitial fibroblasts, eventually representing a common pathway to the progression to ESRD. In transplant recipients, the hypoxic damage might be potentiated by the use of immunosuppressive agents, particularly calcineurin inhibitors, and by the concomitant presence of congestive heart failure, which reduces renal blood flow [19].

Conclusions: From this study, we can conclude that the prevalence of post-transplant anemia is high in pediatric renal transplant patients especially those receiving $\mathrm{CNI}$ and $\mathrm{MMF}$, and it was associated with poorer graft outcome but no effect on patient survival.

\section{References}

1. Vlagopoulos PT, Tighiouart H, Weiner DE, et al.: Anemia as a risk factor for cardiovascular disease and all-cause mortality in diabetes: The impact of chronic kidney disease. J Am Soc Nephrol 2005; 16: 3403-10.

2. Augustine JJ, Knauss TC, Schulak JA, Bodziak KA, Siegel C, Hricik DE: Comparative effects of sirolimus and mycophenolate mofetil on erythropoiesis in kidney transplant patients. Am J Transplant 2004; 4: 2001-6.

3. Mitsnefes MM, Subat-Dezulovic M, Khoury PR, Goebel J, Strife CF: Increasing incidence of post-kidney transplant anemia in children. Am J Transplant 2005; 5: 1713-8.

4. Rigatto C, Foley R, Jeffery J, Negrijn C, Tribula C, Parfrey P: Electrocardiographic left ventricular hypertrophy in renal transplant recipients: Prognostic value and impact of blood pressure and anemia. J Am Soc Nephrol 2003; 14: 462-8.

5. Ponticelli C, Villa M: Role of anaemia in cardiovascular mortality and morbidity in transplant patients. Nephrol Dial Transplant 2002; 17(1): 41-6.

6. Imoagene-Oyedeji AE, Rosas SE, Doyle AM, Goral S, and Bloom RD.: Posttransplantation Anemia at 12 Months in Kidney Recipients Treated with Mycophenolate Mofetil: Risk Factors and Implications for Mortality.J Am Soc Nephrol 2006; 17: 3240-7.

7. Hsu CY, McCulloch CE, Curhan GC.: Epidemiology of anemia associated with chronic renal insufficiency among adults in the United States: Results from the Third National Health and Nutrition Examination Survey. J Am Soc Nephrol 2002; 13: 504-10.

8. Shah N, Al-Khoury S, Afzali B, Covic A, Roche A, Marsh J, Macdougall IC, Goldsmith DJ: Posttransplantation anemia in adult renal allograft recipients: Prevalence and predictors. Transplantation 2006; 81: 1112-8.

9. Afzali B, Al-Khoury S, Shah N, Mikhail A, Covic A, Goldsmith D: Anemia after transplantation. Am J Kidney Dis 2006; 48: 519-36.

10. Winkelmayer WC and Chandraker A: Posttransplantation Anemia: Management and Rationale. Clin J Am Soc Nephrol 2008; 3: S49-S55.

11. Vanrenterghem Y, Ponticelli C, Morales JM et al.: Prevalence and management of anemia in renal transplant recipients: A European survey. Am J Transplant 2003; 3: 835-45.

12. Molnar MZ, Novak M, Ambrus $\mathrm{C}$ et al.: Anemia in kidney transplanted patients. Clin Transplant 2005; 19: 825-33.

13. Winkelmayer WC, Lorenz M, Kramar R, Horl WH, Sunder-Plassmann G.: Percentage of hypochromic red blood cells is an independent risk factor for mortality in kidney transplant recipients. Am J Transplant 2004; 4: 2075-2081.

14. Heinze G, Mitterbauer C, Regele $\mathrm{H}$ et al.: Angiotensinconverting enzyme inhibitor or angiotensin II type 1 receptor antagonist therapy is associated with prolonged patient and graft survival after renal transplantation. $\mathbf{J}$ Am Soc Nephrol 2006; 17: 889-899.

15. Kamar N, Rostaing L.: Negative impact of one-year anemia on long-term patient and graft survival in kidney transplant patients receiving calcineurin inhibitors and mycophenolate mofetil. Transplantation 2008; 85(8):11204.

16. Molnar MZ, Czira M, Ambrus C, Szeifert L, Szentkiralyi A, Beko G, Rosivall L, Remport A, Novak M, Mucsi I.: Anemia is associated with mortality in kidneytransplanted patients-a prospective cohort study. Am J Transplant 2007; 7(4):731-2. 
17. Kovesdy CP, Trivedi BK, Kalantar-Zadeh K, Anderson JE.: Association of anemia with outcomes in men with moderate and severe chronic kidney disease. Kidney Int 2006; 69: 560-4.

18. Rigatto C, Parfrey P, Foley R, Negrijn C, Tribula C, Jeffery J.: Congestive heart failure in renal transplant recipients: Risk factors, outcomes, and relationship with ischemic heart disease. J Am Soc Nephrol 2002; 13: 1084-90.

19. Laina A, Silverberg DS, Wexler D.: Therapy insight: congestive heart failure, chronic kidney disease and anemia, the cardio-renal-anemia syndrome. Nat Clin Pract Cardiovasc Med 2005; 2: 95-100.

20. Gleissner CA, Murat A, Schafer S et al.: Reduced hemoglobin after heart transplantation is no independent risk factor for survival but is associated closely with impaired renal function. Transplantation 2004; 77: 710-7.

21. Behdad Afzali, Salam Al-Khoury, Nilesh Shah, Ashraf Mikhail, Adrian Covic, David Goldsmith: Anemia After Renal Transplantation .AJKD October 2006; Volume 48: Number 4

22. Roger SD, McMahon LP, Clarkson A.: Effects of early and late intervention with epoetin alpha on left ventricular mass among patients with chronic kidney disease (stage 3 or 4): Results of a randomized clinical trial. J Am Soc Nephrol 2004; 15:148-156.

23. Locatelli F, Pisoni RL, Combe C.: Anemia in hemodialysis patients of five European countries: Association with morbidity and mortality in the Dialysis Outcomes and Practice Patterns Study (DOPPS). Nephrol Dial Transplant 2004; 19:121-132.

24. Gouva C, Nikolopoulos P, Ioannidis JP.: Treating anemia early in renal failure patients slows the decline of renal function: A randomized controlled trial. Kidney Int 2004; 66:753-760.

25. Vanrenterghem Y.: Anaemia after renal transplantation. Nephrol DialTransplant 2004; 19: 54

26. Rigatto C, Foley R, Jeffery J, et al.: Electrocardiographic left ventricular hypertrophy in renal transplant recipients: prognostic value and impact of blood pressure and anemia.
J Am Soc Nephrol 2003; 14(2): 462.

27. Djamali A, Becker YT, Simmons WD, et al.: Increasing hematocrit reduce esearly posttransplant cardiovascular risk in diabetic transplant recipients. Transplantation 2003; 76(5): 816.

28. Lorenz M, Winkelmayer WC, Horl WH, SunderPlassmann G.: Anaemia after renal transplantation. Eur J Clin Invest 2005; 35 (3): 89.

29. Winkelmayer WC, Kewalramani R, Rutstein M, et al. Pharmacoepidemiology of anemia in kidney transplant recipients. J Am Soc Nephrol 2004; 15(5): 1347.

30. Karakus S, Kanbay M, Koseoglu HK, et al.: Causes of anemia in renal transplant recipients. Transplant Proc 2004; 36(1): 164 .

31. Chadban SJ, Baines L, Polkinghorne K, Jefferys A, Dogra S, Kanganas C, Irish A, Eris J, Walker R.: Anemia After Kidney Transplantation Is Not Completely Explained by Reduced Kidney Function. Am J Kidney Dis 2007; 49(2):301-9.

32. Yorgin PD, Belson A, Sanchez J, et al: Unexpectedly high prevalence of posttransplant anemia in pediatric and young adult kidney transplant recipients. Am J Kidney Dis 40:1306-1318, 2002

33. Ibrahim, Barbara et al., 1999: Transitions to Adulthood: A National Survey of Egyptian Adolescents. The Population Council, Cairo.

34. Chhabra D, Grafals M, Skaro A, Parker M, and Gallon L Impact of Anemia after Renal Transplantation on Patient and Graft Survival and on Rate of Acute Rejection. CJASN, 2008; 3(4):1168-74.

35. Winkelmayer WC, Lorenz M, Kramar R, Horl WH, Sunder- Plassmann G.: Percentage of hypochromic red blood cells is an independent risk factor for mortality in kidney transplant recipients. Am J Transplant 2004; 4: 2075-81.

36. Offermann G.: Immunosuppression for long-term maintenance of renal allograft function. Drugs 64: 132538, 2004.

37. Nangaku M: Chronic hypoxia and tubulointerstitial injury: A final common pathway to end-stage renal failure. J Am Soc Nephrol 17: 17-25, 2006 